\title{
The Cambrian smorgasbord
}

t began, appropriately enough for research into food webs, over lunch. And appropriately for ambitious and interdisciplinary research, that lunch in 2001 was at the Santa Fe Institute in New Mexico, an organization famous for bringing together creative assemblages of scientists from different fields. Jennifer Dunne, an ecologist at the institute, had been giving a talk about untangling food webs - the networks of who eats who within an ecosystem - by using sophisticated new models. In the audience, and now at her lunch table, was Douglas Erwin, a palaeobiologist based at the Smithsonian Institution in Washington DC. Erwin is, among other things, the curator of the institution's Burgess Shale collection, which despite being more than 500 million years old is one of the best-preserved fossil assemblages in the world.

"We immediately began to brainstorm about whether network analyses could be done with ancient communities," says Dunne. In the past, researchers have assumed that fossil data were not good enough to construct food webs that would be accurate and useful down to the species level; but Dunne's approach, the two thought, might change that. "We weren't sure how the palaeontology community would perceive it," Erwin says. "But we were all pretty excited by the idea." They hoped that it would not merely provide a new look at an ancient community, but that ancient ecologies might cast new light on modern ones, too. Ecologists have shown that modern food webs follow certain rules, such as the distribution of links increasing proportionally with the number of species, or with diversity. But are there universal laws, or are these rules merely a reflection of the world as it happens to be at the moment?

\section{Seeking universals}

Ecosystems on other planets would be a great help in sorting out the necessary from the contingent, but remain stubbornly undiscovered. Mimicry in the lab can't capture the necessary subtlety. Food webs from the fossil record might thus be the closest to something completely different that contemporary researchers can ever hope to get their hands on. And the Burgess Shale fauna from British Columbia, Canada, were the obvious choice. Another lagerstätte ('resting place' - the term for a site of exceptional preservation), the early Cambrian Chengiiang in southern China, was chosen to serve as a comparison. "One major plus of the Cambrian data is that there is excellent soft-body preservation across taxa," says Dunne. "Most fossil assemblages don't



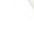


have that." Another plus is that the Cambrian is the period in which predators and prey are first unequivocably present in the fossil record; it's hard to see how there could be interesting food webs any earlier.

In the years after that original lunch, Dunne and Erwin mined existing databases and compiled, reviewed and revised the two Cambrian food webs. "Our first surprise was that we could put these data together," says Dunne. With the food webs ready, the team then analysed them according to the 'niche model' first promulgated by Richard Williams and Neo Martinez ${ }^{1}$.

In the niche model, each predator is constrained to eating from one 'dimension', and is expected to eat everything in that dimension. So if a dolphin eats tuna and sardines, it is presumed to eat everything between the two on that dimension. In practice, such a dimension maps closely to body size, but that's not how it is defined; it is a statistical creation that represents many traits, of which body size simply happens to be a significant one in most systems.

\section{Same old same old}

Just three of the 17 properties of the Burgess Shale web that they measured fell outside the predictions of the niche model. "Most palaeobiologists would assume that these half-billionyear-old food webs should look really different from modern food webs," says Dunne. "But it looks like in most ways, at least that we characterize, the organization looks really similar."

Dunne feels that the overall success suggests that the niche model is capturing something fundamental: the energetics of the system. Food webs are resource distribution networks, and body size or foraging strategies are limited by the energy expended hunting food and the value derived from eating it. "The patterns that we see may reflect not evolutionary history, but the fundamental physics of the system," says Dunne.

"The fact that the patterns seem to be robust and they stand up quite well is very impressive," says Richard Bambach, a palaeoecologist at the Smithsonian.

The clearest difference between then and now is that both Cambrian webs have a higher variability in the number of links per species, something that seems to reflect the higher proportion of predators found in Cambrian fossil assemblages across the world. What this might mean is unclear. Dunne says she thinks there may have been more predators than would be expected today because natural selection hadn't yet weeded out a category of 'hyper-vulnerable' species that modern webs do not have. Conversely, Bambach speculates that the oddities of structure might reflect predators that simply weren't yet very good, with the best of them not good enough to outcompete the rest.
More webs might clarify things. "It would be interesting to do this throughout the fossil record," says Bambach. He has mapped changes in animal life strategies, such as the proportion of motile and non-motile organisms ${ }^{3}$, over geological time and his research suggests that only great extinction events - of which there have been a handful since the Cambrian - are strong enough to break down ecosystems to the point where they reassemble along different lines. That idea may now be testable.

"The general conclusion that basic food-web topology of benthic-dominated marine communities might have been established by the early Cambrian seems to be well supported," agrees Peter Roopnarine, a palaeobiologist at the California Academy of Sciences in San Francisco who has made less well-resolved ecological models of fossil assemblages. But he is not convinced that the apparent similarities between the ancient and modern ecosystems reflect absolute constraints such as those of energy flow. "There could alternatively be fundamental pathways of web assembly that are favoured over others, either by selection at the species level, or selection at the food-web level itself." Roopnarine says that his reconstructions hint at long-term community-level selection based on species' dietary ranges ${ }^{4}$.

But not all palaeobiologists think the new research has much to offer. Nick Butterfield of the University of Cambridge, UK, is unconvinced by the Cambrian webs. The Lobopodian sponge-feeder Aysheaia pedunculata, for example, was a centipede-shaped organism a few centimetres long that resembled today's velvet worms. "Nine specimens of Aysheaia are known to be associated with sponges in the Burgess Shale so the authors say all Lobopodia eat all possible sponges," says Butterfield. "That assumption alone gives them more than 30 connections." The evidence simply doesn't go that far, he says.

To get a grip on such problems, Dunne and her colleagues give each link a certainty value. If fossilized gut contents revealed what the organism had been eating, the link was described as 'certain' - but only $5 \%$ of links, at best, meet that standard. When physical association and morphology indicated a likely interaction, the link was 'probable'; these links comprised roughly a quarter or a half of the total for the Chengjiang and Burgess webs, respectively. When the evidence was mainly morphological and from what their presumed modern-day relatives do, a link was 'possible', as in the case of Aysheaia.
The team estimated their model's sensitivity by removing links, sometimes doing so at random and sometimes according to their likelihood. "In most cases, the results were robust even to the point of pulling out most of the uncertain links," says Dunne. Roopnarine agrees that the technique looks good: "I think it will be adopted broadly as a measure of variance in web reconstruction."

Another method of taking uncertain links into account was working with 'trophic species' rather than true species. A trophic species is defined as a set of organisms that all eat the same thing, and will typically consist of a number of true species. Aysheaia and its apparently close relative Hallucigenia thus collapse into a single trophic species because they both are thought to have fed on sponges, and were in turn fed on by the same predators. Grouping species sacrifices resolution, but can clarify the core functional feeding relationships in a web.

To Butterfield, though, this is folly compounded on folly. "There is no direct evidence that Aysheaia ate sponges; and to assert this and then expand it to include all Lobopodia and all sponges over a period of 10 or 20 million years is laughably absurd," he says. Butterfield suspects that the webs' aptness to niche analysis comes from a circularity in the argument. "This claim that all big things eat all little things instantaneously builds the ecosystem," he says. "They have built the conclusion into their analysis by their assumptions of who's eating who. And that's what we want to know."

Dunne counters by saying that the niche model does not simply assume that big things eat little things; the statistical 'dimension' in the niche is not reducible to a physical dimension. "Insects feed on trees; carnivorous pack animals feed on herbivores that are bigger than them; and parasites feed on much bigger hosts." Would the researchers have identified different trophic relationships if they had been scuba diving in the seas over what would one day be Canada 505 million years ago? "Absolutely," says Erwin. "But would there be enough difference between that and the web we have now to make a difference? Probably not."

\section{Arran Frood is a UK-based science writer.}

1. Williams, R. J. \& Martinez, N. D. Nature 404, 180-183 (2000)

2. Dunne, J. A., Williams, R. J., Martinez, N. D., Wood, R. A. \& Erwin, D. H. PLoS Biol. 6, e102 (2008)

3. Bambach, R. K., Knoll, A. H. \& Sepkoski Jr, J. J. Proc. Nat Acad. Sci. USA 99, 6854-6859 (2002).

4. Roopnarine, P. D., Angielczyk, K. D., Wang, S. C. \& Hertog, R. Proc. R. Soc. B 274, 2077-2086 (2007).

See News Feature, page 714. 